\title{
COMBINED USE OF INFRARED IMAGING TECHNIQUES FOR THE STUDY OF UNDERLYING FEATURES IN THE SANTA MARIA IN COSMEDIN ALTARPIECE*
}

\author{
F. MERCURI, S. CECCARELLI, N. ORAZI, C. CICERO and S. PAOLONI $\dagger$ \\ Department of Industrial Engineering, University of Rome 'Tor Vergata', Rome, Italy
}

\author{
A. C. FELICI
}

Department of Basic and Applied Sciences for Engineering, University of Rome 'Sapienza', Rome, Italy

\author{
F. MATERA \\ Independent restorer, Rome, Italy
}

M. NUZZO

Ministry for Cultural Heritage, Special Superintendence of Archaeology, Arts and Landscape of Rome, Rome, Italy

\section{U. ZAMMIT}

Department of Industrial Engineering, University of Rome 'Tor Vergata', Rome, Italy

\begin{abstract}
This paper presents a study carried out on the painted altarpiece preserved inside the Basilica of Santa Maria in Cosmedin, Rome, by combining three imaging techniques operating in the near-and mid-infrared spectral ranges. The altarpiece has several pictorial layers and restorations, which have superimposed over time for stylistic adjustment and conservative purposes up to its present appearance. The results obtained in this study enable the detection of damage to the wooden support and the identification of pictorial features buried beneath the visible paint layer, thus providing significant information on the historical and artistic characterization of the artefact.
\end{abstract}

KEYWORDS: INFRARED IMAGING, REFLECTOGRAPHY, THERMOGRAPHY, PAINTED ALTARPIECE, DAMAGE, PENTIMENTI

\section{INTRODUCTION}

The present study of the altarpiece of the Basilica of Santa Maria in Cosmedin, Rome, was motivated by historical and artistic reasons concerning its religious role, as well as its provenance and authorship. The painting has undergone several restorations, retouches and stylistic changes throughout its history. The aim of the present work was therefore to provide a depth-resolved non-destructive investigation of the entire layered structure, from the surface to the wooden support. In order to achieve this, a new methodological approach that combines the simultaneous use of different infrared (IR) techniques providing both thermographic and reflectographic

*Received 4 April 2020; accepted 24 December 2020

†Corresponding author: email stefano.paoloni@uniroma2.it

[Correction added on 18 February 2021, after first online publication: In the caption for Figure 1(b), 'short visible (VIS) light' has been replaced with 'infrared thermography (IRT) with short visible (VIS) excitation and MIR detection'.] 
images in different spectral ranges was proposed. Such a methodology relies on the comparative analysis of the images corresponding to layers at different depths within the painting itself in order to understand the artwork's stratigraphic sequence and, therefore, its evolution over time.

The altarpiece is preserved inside the Basilica of Santa Maria in Cosmedin, which dates to the seventh century, and it is nowadays known as the Greek Melkite Catholic Church of Rome. The epithet 'Cosmedin' (from the Greek $\kappa o \sigma \mu \varepsilon \varepsilon \omega$, to adorn) was given in the eighth century to describe the great decorations of its interiors, which are still present. The altarpiece is dedicated to the Mother of God Always Virgin, as claimed by the inscription ' $\Theta E O T O K \Omega I$ AЕIПАР $\Theta E N \Omega I$ ' in Greek characters along the lower edge of the artwork, and it depicts the Virgin Mary holding the Child (Fig. 1, a). In this representation, also identified as the iconography of the Madonna Theotókos (Cavallaro 2013), the two depicted figures wear rich and colourful garments, and they pose in front of a background consisting of a complex black damask pattern stamped on a golden substrate (Nuzzo n.d.). The Child is represented in the characteristic Greek blessing pose holding the globus cruciger while being tenderly embraced by the Virgin's hands.

The painting is in oils on a wooden support of approximately $168 \times 128 \mathrm{~cm}$ in size, which is made by four vertically jointed panels and a thinner horizontal one in the upper side, probably added in recent times.

\section{Origin and authorship}

While the history of the basilica has been extensively recorded over the centuries (Angeli 1902), the history of the altarpiece is documented only by a few literary sources, according to which the painting may be an ancient icon brought to Rome from the East during the iconoclastic persecutions (Crescimbeni 1715, 1719). This assumption may be consistent with the early history of the basilica, and it could be supported by the presence of the Greek inscription. Nevertheless,

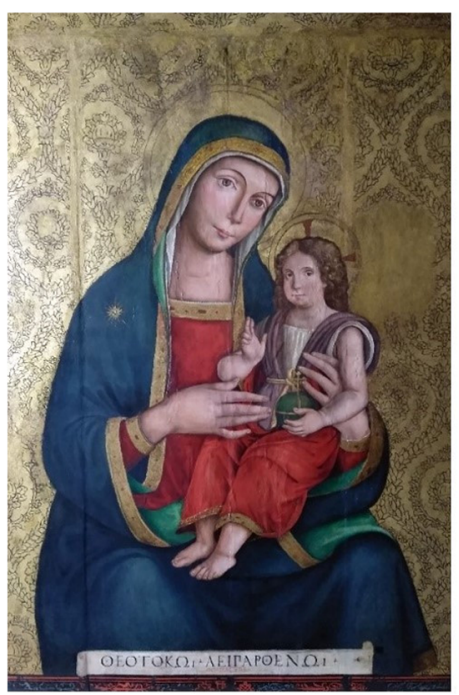

(a)

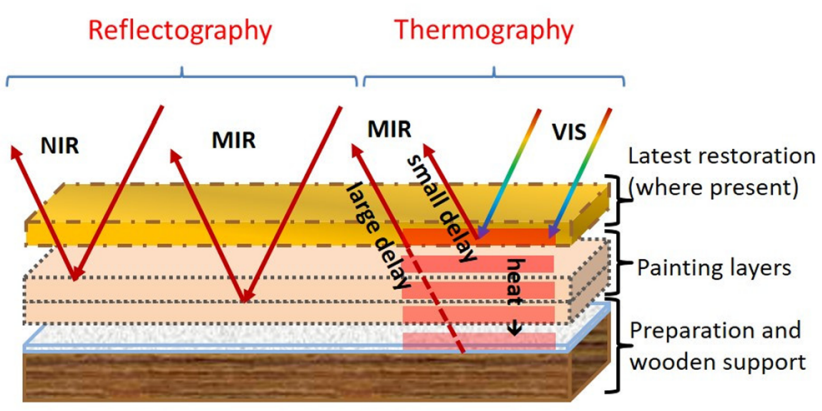

(b)

Figure 1 (a) The Virgin with the Child altarpiece at the Basilica of Santa Maria in Cosmedin, Rome; and (b) a schematic representation of the studied painting's stratigraphy and of the expected penetration depths of the three infrared techniques employed: near-infrared (NIR) reflectography, mid-infrared (MIR) reflectography and infrared thermography (IRT) with short visible (VIS) excitation and MIR detection 
additional hypotheses concerning the altarpiece's origin have been proposed over the last century. Several scholars suggest it could be a medieval icon completely covered by a 'modern' painting (Giovenale 1927; Cavallaro 1992; Russo 2013). Recently, the discovery of the inscription 'IO PIACERE', which was revealed on the title block during the latest restoration, provided further insight about the dating and authorship of the altarpiece. The inscription has been interpreted as the signature of Giovanni Piacere, an Italian artist working in central Italy during the 15 th century (Nuzzo n.d.).

\section{The role of worship}

The oldest literary sources document several miracles associated with the Madonna Theotókos of Santa Maria in Cosmedin (Crescimbeni 1715, 1719), which are consistent with the role of important worship played by the altarpiece throughout its history. This is an important to remember as it might have influenced the nature of past restorations, which were probably aimed at mainly preserving the religious role of the painting rather than its artistic function.

What is briefly reported above points out the importance of undertaking the study and discovering the characterization of the sequence of the changes made over time on the pictorial layers of the artwork. With this aim, an imaging analysis of the entire altarpiece was performed by means of thermographic and reflectographic techniques in two different IR spectral ranges. The different images obtained by the different techniques could be related to features located at different depths in the artwork and then analysed comparatively to understand the evolution over time of the painting layers.

\section{MATERIALS AND METHODS}

Three different IR imaging techniques were employed, namely, near-infrared (NIR) reflectography, active infrared thermography (IRT) and mid-infrared (MIR) reflectography, the first operating in the near-IR $(0.75-1.1 \mu \mathrm{m})$ spectral range and the other two in the mid-IR (3-5 $\mu \mathrm{m}$ range). The choice of using such a combined experimental approach is related to the different capability each technique grants in penetrating through the surface and subsurface layers of the artwork, as shown in Figure 1 (b). Thus, as discussed below, reflectography in the NIR range can detect, for example, even shallow paint retouches performed on the artwork, while that in the MIR range also detects preparatory drawings, pentimenti and fillings performed to mend gaps in the paint layer and/or preparatory layer. IRT, particularly when performed with large delay times, can also detect defects located deeper in the artwork, such as gaps and detachments situated in the preparatory layer or even in the wooden support, because of its sensitivity to the in-depth heat diffusion process. It is also worthwhile pointing out that the results provided by each technique may be affected by specific limitations deriving from the adopted instrumentation or by constraints imposed by particular conservation requirements. The spatial resolution of the images recorded in the MIR range by reflectography and thermography, because of the characteristics of the mid-IR camera, is rather poor when compared with that of the NIR range image obtained with detectors with a much larger number of pixels, which therefore ensure a better definition of the sample details. All such imaging techniques induce the artefact surface heating which must be kept at a minimum. In the thermographic investigations in this work, the distance from the painting to the flash lamps and their power were set so that a very brief temperature increase was induced by the light absorption at the painting not exceeding about $10^{\circ} \mathrm{C}$. Concerning the NIT and MIR reflectographies, the exposure time to the incident continuous 
radiation was limited to a few seconds so as to induce a very small temperature increase in the order of a very few degrees Celsius.

\section{Near-infrared (NIR) reflectography}

In cultural heritage investigations, NIR reflectography has been successfully employed for revealing pentimenti and underdrawings thanks to the capability of the NIR radiation to propagate through the pictorial layers with respect to the visible radiation (Hain et al. 2003; Cocco et al. 2009; Daffara and Fontana 2011; Cucci et al. 2013). In fact, this technique takes advantage of the smaller degree of scattering that affects the NIR radiation with respect to the visible one, thus providing optical access to the subsurface features of the investigated object (Delaney et al. 2009). The visibility of the underlying features depends on several factors, among which are the paint layers' thickness and chemical composition (Felici et al. 2004; Bonifazzi et al. 2008; Cucci et al. 2016; Ceccarelli et al. 2018). In the present study, the NIR images mainly highlight the features located just beneath the surface layer, which in the case of the altarpiece corresponds to the visible painting and to the latest restoration retouches.

In this study, NIR images were collected with a low-noise digital charged coupled device (CCD) camera, cooled with a Peltier device and equipped with a bandpass filter at $1000 \mathrm{~nm}$. The CCD sensor (Kodak KAF8300) consists of a matrix of $3348 \times 2574$ silicon pixels. The images were processed using MaxImLE acquisition software in order to subtract the CCD sensor dark noise and enhance the contrast of the displayed elements. The sample was illuminated by means of two OSRAM SICCATHERM ${ }^{\circledR}$ IR lamps, with their maximum emitted intensity in the spectral range of $1.1-1.2 \mu \mathrm{m}$. The incident NIR radiation was diffused so as to reduce as much as possible the reflected component from the varnish layer on the painting surface. The recorded image corresponded to a painting area of about $65 \times 50 \mathrm{~cm}^{2}$.

\section{Mid-infrared (MIR) reflectography}

IR reflectography operating in the mid-wave IR range was recently introduced in cultural heritage investigations (Daffara et al. 2018; Mercuri et al. 2018c), thus extending the exploited spectral range in comparison with the NIR and shortwave infrared (SWIR) regions. MIR reflectography also makes use of the low level of scattering of the MIR radiation in the propagation through the surface layers (Mercuri et al. 2018c). In addition, in this spectral range, pigments have usually different absorption and scattering properties with respect to those in the NIR range. Thanks to such a circumstance, MIR reflectography enables the detection of elements of different composition and located at greater depth in comparison with those detected by means of the NIR reflectography. Therefore, it can provide images of features located deeper in the artefact, corresponding, for instance, to a preparatory drawing or to an underlying painting, more effectively than the NIR reflectography (Ibarra-Castanedo et al. 2010; Mercuri et al. 2018c; Sfarra et al. 2018).

In the MIR reflectography set-up, the continuous sample illumination was carried out by means of carbon filament IR sources, positioned about $1 \mathrm{~m}$ from the painting, and whose radiation was directed at a $45^{\circ}$ incidence angle, which showed a substantial emission component in the 3-5 $\mu \mathrm{m}$ wavelength range corresponding to that of the spectral sensitivity of the employed IR camera. Special care was taken to minimize the exposure time (approximately $0.1 \mathrm{~s}$ ) and the power of the incident IR radiation $(<100 \mathrm{~W})$ to reduce the emitted component of the mid-wave 
IR radiation related to the sample heating, thus making the image contrast mainly originate from local differences in the IR radiation reflection from the painting layers.

MIR reflectography and IRT images were consecutively recorded on the same sample area by means of the same IR camera, thus ensuring the exact correspondence to the recorded images and of the investigated sample area. The employed IR camera was a CEDIP Jade III operating with a $320 \times 240$ pixels InSb focal plane array, sensitive in the $3-5 \mu \mathrm{m}$ mid-wave IR range. The distance between the painting and the IR camera was such that features spaced about $0.1 \mathrm{~mm}$ could be resolved. Altair software was used for the acquisition of all the MIR images obtained by both the reflectographic and the thermographic methods.

\section{Infrared thermography (IRT)}

IRT is one of the so-called photo-thermal techniques, based on the thermal analysis of samples heated by light absorption, that have been extensively used for the determination of different thermal parameters of different kind of materials (Marinelli et al. 1995; Marinelli et al. 1996; Zammit et al. 1988, 2011; Maldague 2001; Mercuri et al. 2003; Gavrilov et al. 2014; Paoloni et al. 2016). Concerning cultural heritage investigations, IRT has been successfully used for the characterization of structural and the subsurface features in a large variety of artefacts (Daffara and Fontana 2011; Mercuri et al. 2013a, 2013b, 2017a, 2017c, 2018a; Doni et al. 2014; Pucci et al. 2015; Orazi et al. 2016, 2019).

The pulsed IRT configuration employed in this study consists of the recording of the temperature transient at the sample surface following the heating induced by the absorption of a short visible (VIS) light pulse. The temperature detection is carried out by means of an IR camera that provides maps of the locally emitted IR radiation, thereafter referred to as thermograms, which are recorded as a function of time during the cooling process of the artefact.

The presence of inhomogeneities beneath the artefact surface affects the local heat propagation, thus inducing a non-uniform temperature distribution at the surface whose analysis enables the characterization of the detected subsurface features (Philippi et al. 1995; Candore et al. 2012; Blessley et al. 2014; Di Tuccio et al. 2015; Mercuri et al. 2017b, 2018b).

In comparison with the reflectographic techniques described above, IRT can probe the sample structure over a depth greater than the penetration depth of the probing radiation beam thanks to the temperature field, induced by the pulse heating, associated with the light absorption, diffusing with time throughout the sample thickness. Because of this effect, it is possible to probe deeper into the artefact by increasing the delay time at which the thermogram is recorded with respect to the heating light pulse. Therefore, the images obtained by means of the IRT offer the opportunity to probe the painting's stratigraphic structure over a greater depth extending even to the wooden support.

For the present thermographic investigations, two halogen flash lamps (Bowens Estime 3,000, maximum power of $650 \mathrm{~W}$ ) were employed to produce approximately 2 -ms light pulses. The spectral emission of the lamps extends to the entire visible range with also a minor component in the IR range. Because of that, adequate filters were placed in front of the flash lamps to cut off such an IR component and prevent unwanted reflections superimposing on the mid-wave IR radiation emitted by the heated sample. The lamps were positioned at a distance of $0.5 \mathrm{~m}$ with their axes at $45^{\circ}$ with respect to the altarpiece surface. The thermographic sequences of the images were recorded for $1 \mathrm{~s}$ in full-frame mode with a $150 \mathrm{~Hz}$ frame rate. The IRT is typically employed in the two main spectral ranges of sensitivity of the detector, 3-5 and $8-14 \mu \mathrm{m}$, respectively. The former range was chosen since, for equal temperature difference between an 
object and its background, it is shown in the literature that the thermal contrast is approximately twice as large compared with the 8-14 $\mu \mathrm{m}$ range (Gaussorgues 1994). The choice of the 3-5 $\mu \mathrm{m}$ range also allowed the use of the same IR camera for both the MIR thermography and reflectography, ensuring the perfect image correspondence to the reflectograms and the thermograms to be comparatively analysed.

The thermograms considered were mostly those obtained with 20 and 400 ms delays. The former corresponded to the beginning of the cooling process, so as to have thermographic information originating from near the surface region, while the latter corresponds to one of the largest delay values compatible with an acceptable signal-to-noise ratio. The processing of the IRT image sequence included pixel-by-pixel subtraction of the image obtained before the light pulse which improved the dynamic range the thermograms. To make the comparison with the reflectographic images more effective, the thermograms shown here are presented with an inverted grey palette according to which the hotter areas appear darker.

For the investigation of the painting presented, the combined use of the above-mentioned techniques will ensure an effective in-depth analysis capability enabling the detection of most of the graphical and pictorial features buried beneath the surface of the pictorial layer, and also the evaluation of the conservation state of the wooden support.

\section{RESULTS AND DISCUSSION}

The results obtained by means of the three employed imaging techniques are now discussed and compared. As shown below, several additional graphical and pictorial elements, with respect to those visible at the surface of the painting, are revealed, thus confirming the complex layered structure of the altarpiece. Both the painting layer and the adhesion to the wooden support showed good conservation conditions, even though, based on the number and extension of the detected retouches, the painting areas corresponding to the panel's junctions can be considered as those most severely affected by damage. The details of the restoration and stylistic changes detected by the IR imaging carried out in this work are also presented and discussed.

\section{The Virgin Mary}

In the analysis of the Virgin's face (Fig. 2, a), two frames of the thermographic sequence revealed the in-depth extension of the defects of the wooden support. In particular, Figure 2 (b) reports the thermogram recorded shortly after $(20 \mathrm{~ms})$ the heating light pulse. It displays two vertically oriented defects, running across both eyes (indicated by the arrows), which have been repaired by a recent restoration. The damage across the right eye also runs between the nose and the mouth, in correspondence to the panel joint where the restoration is evident. The origin of such damage has been associated with the mechanical stress usually involving the surroundings of the joints. Under the left eye, a small-restored void can also be observed (marked by the circle in Fig. 2, b). This thermogram, recorded immediately after the light pulse, was generated by the mid-IR emission that comes only from the outermost pictorial layers, those in which the incident visible light, while being diffused, is able to penetrate and get absorbed.

The thermogram recorded with a larger delay $(400 \mathrm{~ms})$ reported in Figure 2 (c) shows basically the same elements highlighted in Figure 2 (b), but, in correspondence to the vertical damage on the left, the thermogram also displays some aligned dark (hotter) spots (indicated by the arrow), presumably corresponding to areas where the thermal contact with the substrate is poorer. This could indicate the presence of detachments or of filled gaps below the paint layer, perhaps down 


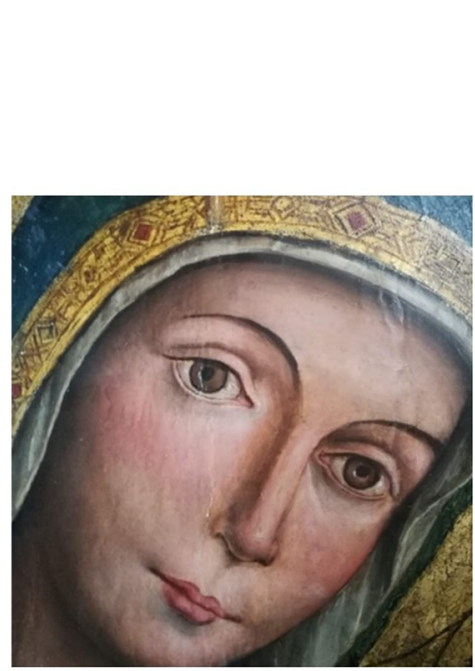

(a)

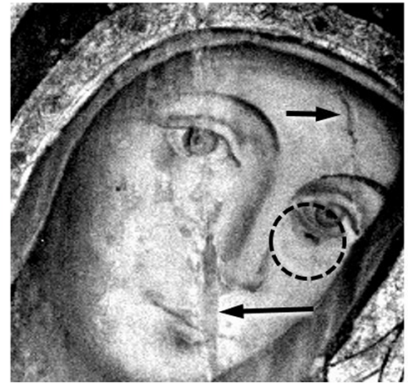

(b)

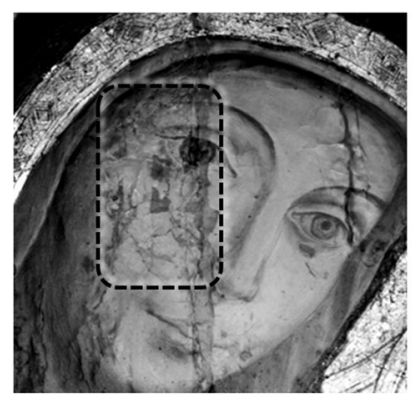

(d)

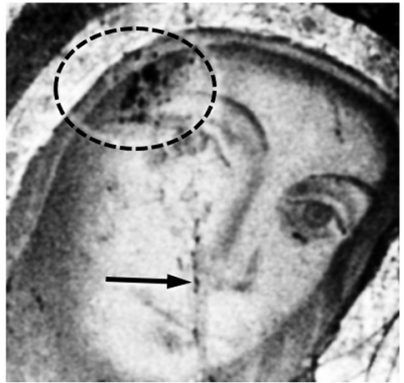

(c)

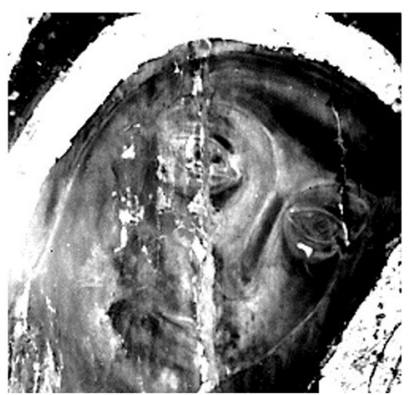

(e)

Figure 2 (a) Detail of Figurel(a); (b) an active infrared thermography (IRT) image recorded after $20 \mathrm{~ms}$, the light pulse revealing subsurface damage in the pictorial layer (arrows); (c) an IRT image recorded at a larger delay (400 ms) revealing subsurface damage to the wooden support (arrows and circle); (d) a near-infrared (NIR) reflectogram highlighting subsurface damage in the paint layer (dashed square); and (e) a mid-infrared (MIR) reflectogram revealing different details with respect to the NIR reflectogram and additional sub-superficial damages (rectangle). The dashed circles mark a small restored void.

to the wooden support. Similar kinds of defects, highlighted by the circle, are also revealed on the right temple. Given the considerable value of the thermogram acquisition-delay time, the probed depth probably extends beyond the preparatory layer, down to the wooden support. In this case, in fact, the heat generated at the most superficial level, where the VIS light can penetrate and be absorbed, has had time to propagate to a deeper level where the presence of eventual inhomogeneous features affects the heat-diffusion process. This, in turn, generates local differences in temperature inducing different amounts of emitted IR radiation. That emitted in the spectral range of 3-5 $\mu \mathrm{m}$ can travel back to the IR camera through the overlying layers of the painting, maintaining a substantial unscattered component. This gives rise to the generation of the contrasted features in the thermogram displaying the buried elements.

The vertical line defects and the lacuna under the left eye are also detected in the NIR and MIR reflectographic images (Figs 2, d, e). The reflectographic images reveal an additional subsurface branched cracked area on the right-hand side of the face (framed by the rectangle in Fig. 2, d), probably corresponding to areas of restored craquelures. As pointed out above, in the NIR range the reflectogram reveals mainly features in the visible pictorial layer, such as retouches, to be ascribed to the latest restoration, while the MIR reflectogram also provides a map of the structural repairs beneath it, mostly corresponding to fillings of the paint voids left by detached fragments. Finally, it is very interesting to note that what appears as a vertical crack crossing the left eye in the NIR and MIR reflectographs and also in the thermogram obtained with the $20 \mathrm{~ms}$ delay is 
only barely detectable in the thermogram performed with the $400 \mathrm{~ms}$ delay, indicating that the in-depth extension of the defect is probably only limited to the paint layer. This consideration, together with those made above concerning the other detected defects, helps in understanding the effectiveness of the multi-imaging approach to retrieve the relative depth positioning of the observed subsurface features.

The close-ups of the Virgin's face (Fig. 3) provide additional information about the painting layers. In particular, the thermogram (Fig. 3, b, obtained with a $20 \mathrm{~ms}$ delay) and the NIR reflectogram (Fig. 3, c) show the outlines and the shades of the nose (indicated by the arrows), while the MIR reflectogram (Fig. 3, d) discloses pictorial features beneath the visible surface paint layer, revealing a different rendering of the Virgin's physiognomy. In particular, the facial traits highlighted by the MIR reflectography (Fig. 3, d) show a rounder-shaped eye, a narrower nose with a differently shaped tip and the eyebrows lines extending closer to the nose (the arrows in Fig. 3, d).

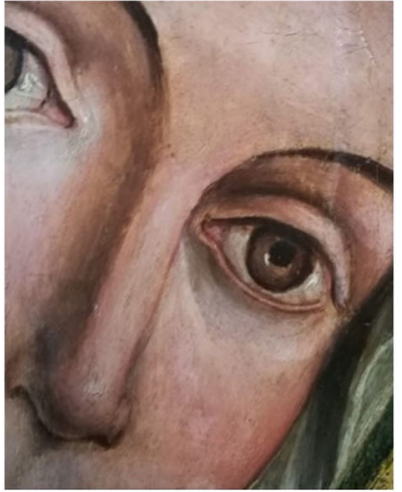

(a)

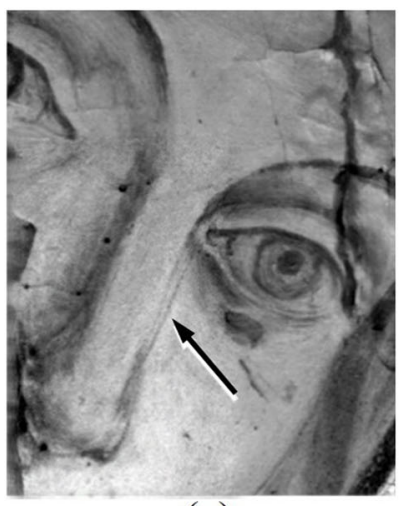

(c)

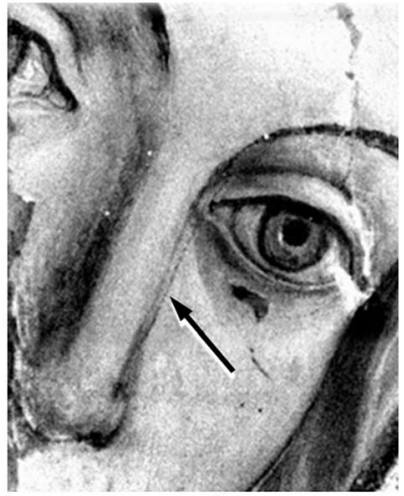

(b)

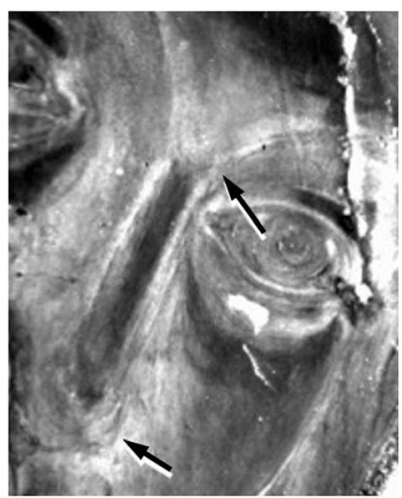

(d)

Figure 3 (a) Detail of Figure1(a); (b) an active infrared thermography (IRT) image recorded after $20 \mathrm{~ms}$ from the light pulse; (c) a near-infrared (NIR) reflectogram that allows the better appreciation of the shades on the Virgin's face and the outlines of her nose (arrows); and (d) a mid-infrared (MIR) reflectogram disclosing the pictorial features beneath the superficial layer (a thinner nose and eyebrows extending closer to the nose). All images show the vertically oriented defects on the wooden support and the restored void detected in Figure2. 


\section{The blessing Child}

Interesting results were also obtained by the combined analysis of the Child (Fig. 4, a), revealing differences between the visible and the subsurface layers of the painting where damaged and restored areas could be detected. In particular, in the area of the Child's hair, the IRT image (Fig. 4, b, 20 ms delay) shows several inhomogeneities, such as those indicated by the arrows. The central (dark) part of the defect at the top of the head and of those on the right are not visible in the NIR (Fig. 4, d) and MIR (Fig. 4, e) reflectograms, so their contrast generation in the thermogram should be ascribed to thermal factors rather than optical ones. Therefore, they probably correspond to detachments repaired during previous restorations. Moreover, they are barely detectable in the thermogram obtained with a delay of about $200 \mathrm{~ms}$ (Fig. 4, c), indicating even in this case that they do not extend much beyond the surface paint layer. Moreover, in the same area, NIR and MIR reflectographies identify subsurface cracks beneath the restored surface paint layer similar to those observed on the Virgin's face and, even in this case, probably associated with mechanical stress effects.

Finally, the MIR reflectogram clearly reveals a variation in the Child's hair profile on the right-hand side of the image, with respect to that portrayed in the picture. More specifically, the NIR reflectogram and the thermogram obtained with the small delay display voluminous and curly hair, as indicated by the arrow in Figure 4 (c), while the hair profile detected by the

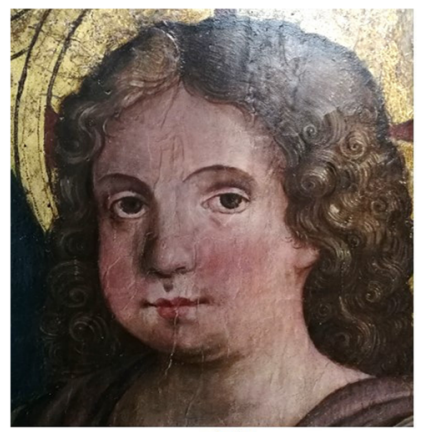

(a)

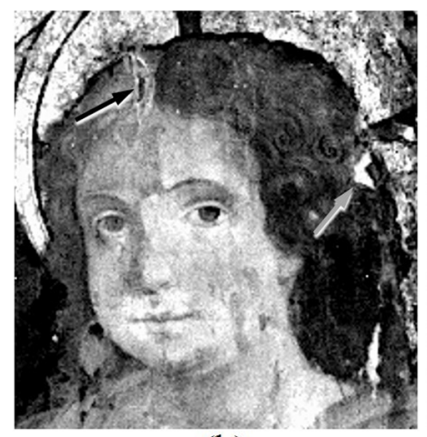

(b)

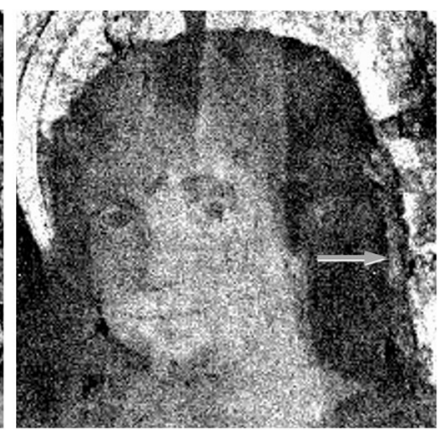

(c)

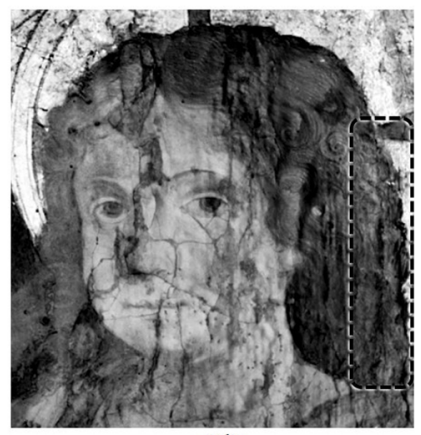

(d)

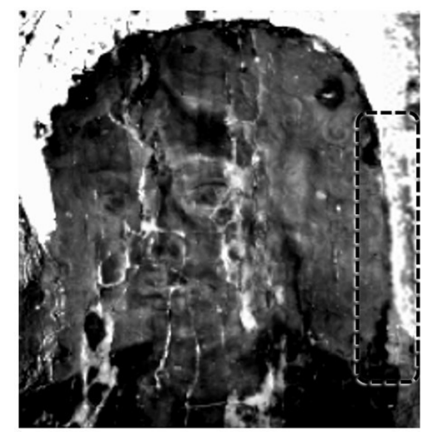

(e)

Figure 4 (a) Detail of Figure1 (a); (b) a thermogram (recorded after $20 \mathrm{~ms}$ from the light pulse) that detects structural damage and detachments indicated by the arrows; (c) a thermogram (recorded after $400 \mathrm{~ms}$ from the light pulse); (d) a near-infrared (NIR) reflectogram revealing a subsurface crack); and (e) a mid-infrared (MIR) reflectogram that reveals a different hair profile with respect to that shown in the picture and compared with (d) (dashed rectangles). 
MIR reflectography extends over a more restricted area (dashed rectangle in Fig. 4, e). The two different hair profiles could be detected, though much less clearly, even in the thermogram obtained with the larger delay (Fig. 4, c), where the area corresponding to the modified part of the hair profile appears slightly lighter (arrow). Thus, once again, the multi-imaging analysis has granted the possibility to retrieve the relative depth positioning of the observed subsurface features. In particular, it is confirmed that those observed by the NIR reflectography originate just beneath the latest paint retouches, while those observed in the MIR reflectogram and in the larger delay thermograms correspond to deeper layers, presumably originating from the earlier version of the painting as in the case of the Virgin's face.

Further changes and inhomogeneity can also be observed in the other areas of the painting, such as in correspondence to the Child's hand (Fig.5, a). Here, the IRT, NIR and MIR images disclose the absence of the right thumb of the Child at all investigated depths, denoting the almost complete loss of the pictorial layer in that area in the past (dashed squares in Fig. 5, b-e).

In particular, Figure $5(\mathrm{~b}, \mathrm{c})$ shows the thermographic image recorded shortly after the flash pulse $(20 \mathrm{~ms})$ and at larger delay time $(300 \mathrm{~ms})$, respectively. The latter highlights some deeper cracks (indicated by the arrow) running between the restored thumb and the palm, along the boundary of the lost pictorial area.

Additional defects in correspondence to the panel's junction extended down to the area of the Child's feet (Fig. 6, a), as shown in the framed areas in Figure 6 (b-d). Moreover, a defect just below the paint retouches is disclosed on the left foot by the NIR reflectogram, indicated by the arrow in Figure 6 (c). Finally, all the IR images also reveal differences in feet shape and position from those observed in the visible painting (Fig. 6, a). In fact, the IRT most clearly, and, to a lesser extent, also the NIR and MIR reflectographies, detect an original profile shifted with respect to that visible nowadays.

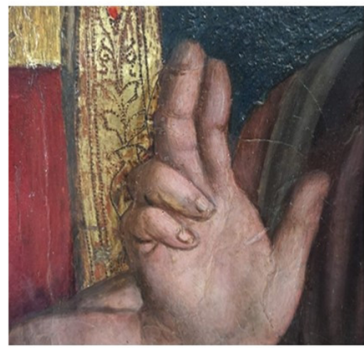

(a)

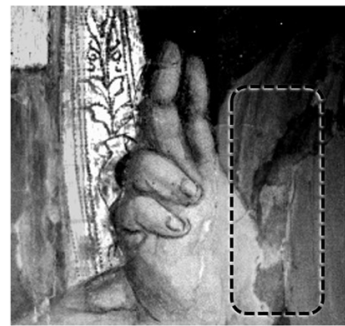

(b)

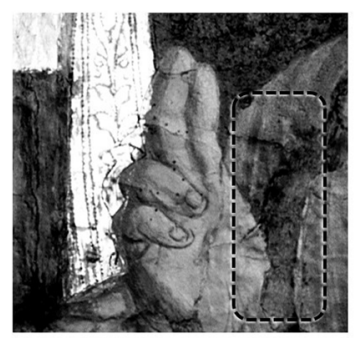

(d)

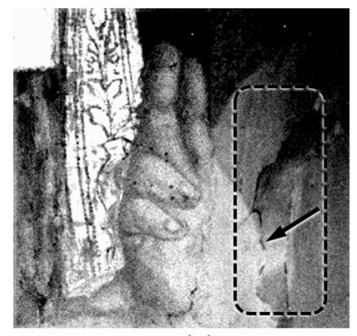

(c)

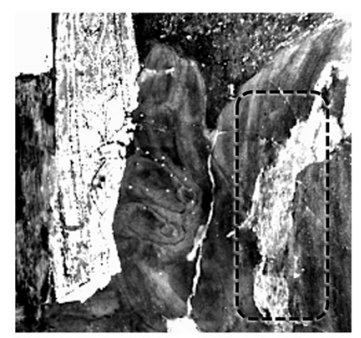

(e)

Figure 5 (a) Detail of Figurel (a); (b, c) thermograms recorded with different delays (20 and $300 \mathrm{~ms}$, respectively) disclose the absence of the thumb, which is also revealed in the near-infrared (NIR) and mid-infrared (MIR) reflectograms (d and e, respectively). 


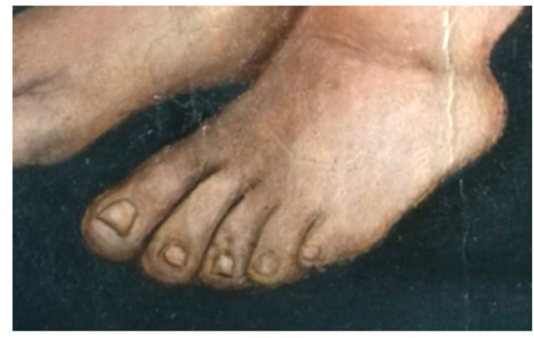

(a)

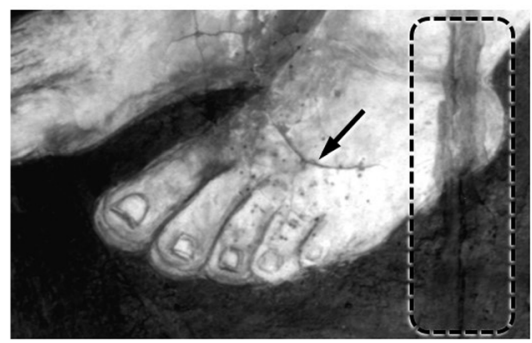

(c)

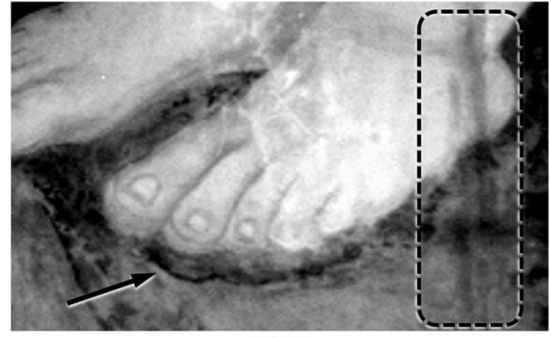

(b)

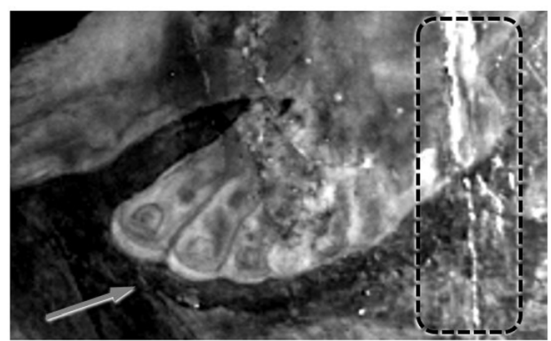

(d)

Figure 6 (a) Detail of Figure (a); (b) an active infrared thermography (IRT) image (recorded after $20 \mathrm{~ms}$ from the light pulse) that detects the repair in correspondence to the panels' junction (dashed rectangle) and a pentimento on the position of the feet, indicated by the arrow; (c) a near-infrared (NIR) reflectogram that reveals the same elements shown in (b) and an additional subsurface defect in the painting layer (dashed arrow on the left foot); and (d) a mid-infrared (MIR) reflectogram showing the pentimento (pointed out by the arrow) and the panels' junction defect (dashed rectangle).

The obtained results have shown several subsurface features, some of which corresponded to restored defects, and other to pre-existing graphical features which indicated a different physiognomy for the Virgin. The pictorial and graphical elements highlighted here can provide useful information for the historical and artistic placement of the artwork, which is surely composed of several overlapping layers of paint, restorations and adjustments made over the centuries. In particular, the investigations brought to light several buried pictorial elements with different stylistic features with respect to what currently portrayed, which recent studies (Nuzzo n.d.) ascribe to the original draft of the painting. According to such studies, because of the attribution of the original work to the 15th-century painter Giovanni Piacere and of the renewed artistic interest in icons in Rome at the end of that century, the dating of the painting should be placed in that period. This would outdo the assumptions reported in the previous literature, starting in the 17th century, which dated the first draft of the altarpiece to late antiquity or the Middle Ages. The stratified multiple repaintings that have taken place over the following centuries witness the preservation history of the artefact because of its worship function.

The discussion of the obtained results has made it evident that the comparative analysis of the images with different probing depth capability enabled the detection of the reported stylistic differences which are of great importance for the understanding of the painting genesis. Some overlapping information was found in some of the reflectographic and thermographic results at small delays, but the thermography with a large delay in most cases also provided supplementary data. The information that each technique can provide largely depends on its capability to refer the revealed elements to a specific painting level. This can be achieved 
successfully if, in the analysis of the images by each technique, the specific physical phenomena underlying the image generation process are correctly accounted for. This is not always trivial when applied to semi-transparent materials, such as those of the paintings, where optical and thermal processes are involved in the generation of reflectograms and thermograms. A real quantitative analysis of the buried elements, such as the determination of their absolute depth, involves the evaluation of parameters such as the VIS and IR light absorption, materials' emissivity coefficients and thermal diffusivity. This is made difficult in the analysis of paintings by the inhomogeneous nature of the stratified layers, unlike the case of more homogeneous semi-transparent artefacts, such as the paper-based ones (Caruso et al. 2019). Nevertheless, it could be shown that the time evolution analysis of the thermograms sequence in the case of paintings, combined with the reflectographic results, can provide information on the relative depth of the detected subsurface elements and reveal their possible different nature. Hence, the contribution of IRT in the proposed combined approach is, in general, not limited only to the confirmation of the detection of the elements also revealed by other NIR and MIR imagings. On the contrary, thanks to the image generation depending on thermal as well as optical parameters, the thermograms could detect subsurface elements not revealed by the reflectographies, and could provide a useful tool for the in-depth ordering of the features detected by all the IR imaging techniques.

\section{CONCLUSIONS}

The combined use of three IR imaging techniques was presented for the non-destructive investigation of a painting on a wooden panel preserved at the Basilica of Santa Maria in Cosmedin in Rome. In particular, NIR and mid-wave IR spectral regions were exploited for the depth-resolved characterization of the altarpiece by means of thermographic and reflectographic techniques. The proposed investigative methodology allowed us to obtain extensive information concerning the multiple layered structure of the altarpiece by revealing features buried beneath the visible painting which provided a mapping of the restorations and the stylistic changes.

The structural mapping showed damage extending over the greater part of the altarpiece, most of it presumably caused by mechanical stress along the panel's four junctions. In addition, a damaged area, extending from the face to the left hand of the Child, could also be detected. The overlapping over the centuries of multiple painting layers has probably contributed to make the damage related to thermal-hygrometric phenomena more severe. In fact, the areas where retouches were more extensively applied corresponded to those mostly affected by voids and detachments consequent to craquelures-like dynamics.

The investigation of the altarpiece's pictorial layers brought to light several repaintings, pentimenti and differences between the visible features of the painting and those revealed in the subsurface levels. All these features describe an intensively adjusted artwork, possibly because of the religious importance of the altarpiece, which may have been required to be subject to stylistic changes in order to maintain the iconography and its worship function over time rather than its artistic identity. In particular, by exploring the different levels of the painting, the MIR reflectograms revealed a hidden rendering of the Virgin's face associated with the original work of the 15 th century and different to that portrayed at the surface. The combined use of NIR and IRT imaging meant more superficial layers could be inspected, where it was possible to document the changes applied in more recent times by repaintings and restorations. 


\section{ACKNOWLEDGEMENTS}

The authors are very gratefully to Padre Chihade Abboud, Rector of the Basilica of Santa Maria in Cosmedin, for allowing the investigations on the altarpiece. The study was performed within the framework of the ADAMO project produced by the Centre of Excellence for the District of Technologies for Culture (DTC) of the Lazio Region. The data that support the findings of this study are available from the corresponding author upon reasonable request.

\section{PEER REVIEW}

The peer review history for this article is available at https://publons.com/publon/10.1111/ arcm.12653.

\section{REFERENCES}

Angeli, D., 1902, Le chiese di Roma, guida storica e artistica delle basiliche, chiese e oratorii della città di Roma, Casa Editrice Dante Alighieri 295-9. https://archive.org/details/lechiesediromagu00ange_0/page/n679/mode/2up

Blessley, K., et al., 2014, The feasibility of flash thermography for the examination and conservation of works of art, Studies in Conservation, 55(2), 107-20. https://doi.org/10.1179/sic.2010.55.2.107

Bonifazzi, C., et al., 2008, A scanning device for VIS-NIR multispectral imaging of paintings, Journal of Optics A: Pure and Applied Optics, 10(6), https://doi.org/10.1088/1464-4258/10/6/064011

Candoré, J. C., et al., 2012, Non-destructive testing of works of art by stimulated infrared thermography, The European Physical Journal Applied Physics, 57(2) Available at, https://doi.org/10.1051/epjap/2011110266

Caruso, G., et al., 2019, Quantitative evaluations by infrared thermography in optically semi-transparent paper-based artefacts, Measurement: Journal of the International Measurement Confederation, 143, 258-66. https://doi.org/ 10.1016/j.measurement.2019.04.086

Cavallaro, A., 1992, Antoniazzo Romano e gli antoniazzeschi, Campanotto, Udine, EAN: B01CVTUUS4.

Cavallaro, A., 2013, Antoniazzo Romano, pittore 'Dei migliori che fussero allora in Roma', in Antoniazzo Romano pictor urbis, 20-47.

Ceccarelli, S., et al., 2018, Laser scanners for high-quality 3D and IR imaging in cultural heritage monitoring and documentation, Journal of Imaging., https://doi.org/10.3390/jimaging4110130

Cocco, O., Forcellino, A., and Persia, F., 2009, NIR Reflectography applied to the study of Marcello Venusti' s three Panels, DGaO Proceedings 2009, ISSN: 1614-8436.

Crescimbeni, M., 1715, L'Istoria della basilica di S, Maria in Cosmedin di Roma Ordine della Generale Adunanza degli Arcadi.

Crescimbeni, M., 1719, Stato della basilica diaconale, collegiata e parrocchiale di S, Maria in Cosmedin di Roma.

Cucci, C., Delaney, J. K., and Picollo, M., 2016, Reflectance hyperspectral imaging for investigation of works of art: Old master paintings and illuminated manuscripts, Accounts of Chemical Research, 49(10), 2070-9. https://doi.org/ 10.1021/acs.accounts.6b00048

Cucci, C., et al., 2013, Extending hyperspectral imaging from Vis to NIR spectral regions: A novel scanner for the in-depth analysis of polychrome surfaces, Optics for Arts, Architecture, and Archaeology IV, 8790, pp. 879009-1-9, https://doi. org/10.1117/12.2020286

Daffara, C., and Fontana, R., 2011, Multispectral infrared reflectography to differentiate features in paintings, Microscopy and Microanalysis, 17(5), 691-5. https://doi.org/10.1017/S1431927611000031

Daffara, C., Parisotto, S., and Ambrosini, D., 2018, Multipurpose, dual-mode imaging in the 3-5 $\mu \mathrm{m}$ range for artwork diagnostics: A systematic approach, Optics and Lasers in Engineering, 104(June 2017), 266-73. https://doi.org/ 10.1016/j.optlaseng.2017.10.006

Delaney, J. K., et al., 2009, Visible and infrared reflectance imaging spectroscopy of paintings: Pigment mapping and improved infrared reflectography, Heritage Science, 7391, 739103. https://doi.org/10.1117/12.827493

Di Tuccio, M. C., et al., 2015, Thermographic inspection of cracks in the mixed materials statue: Ratto delle Sabine, Heritage Science, 3(1), 10. https://doi.org/10.1186/s40494-015-0041-6

Doni, G., et al., 2014, Thermographic study of the illuminations of a 15th century antiphonary, Journal of Cultural Heritage, 15(6), 692-7. https://doi.org/10.1016/j.culher.2013.12.001 
Felici, A. C., et al., 2004, The wall paintings in the former refectory of the Trinità Dei Monti convent in Rome: Relating observations from restoration and archaeometric analyses to Andrea Pozzo's own treatise on the art of mural painting, Journal of Cultural Heritage, 5(1), 17-25. https://doi.org/10.1016/j.culher.2003.07.001

Gaussorgues, G., 1994, Infrared Thermography, Springer Netherlands, 11-60. https://doi.org/10.1007/978-94-011-0711-2

Gavrilov, D., Maev, R. G., and Almond, D. P., 2014, A review of imaging methods in analysis of works of art: Thermographic imaging method in art analysis, Canadian Journal of Physics, 92(4), 341-64. https://doi.org/10.1139/cjp2013-0128

Giovenale, G. B., 1927, La basilica di S, Maria in Cosmedin, Roma.

Hain, M., Bartl, J., and Jacko, V., 2003, Multispectral analysis of cultural heritage artefacts, Measurement Science Review, 3(1), 9-12.Available at:. http://www.measurement.sk/2003/S3/Hain.pdf

Ibarra-Castanedo, C., et al., 2010, Diagnostics of panel paintings using holographic interferometry and pulsed thermography, Quantitative InfraRed Thermography Journal, 7(1), 85-114. https://doi.org/10.3166/qirt.7.85-114

Maldague, X., 2001, Theory and practice of infrared Technology for Nondestructive Testing, Wiley, ISBN: 978-0-47118190-3.

Marinelli, M., Mercuri, F., and Belanger, D. P., 1995, Specific heat, thermal diffusivity, and thermal conductivity of FeF2 at the Néel temperature, Physical Review B, 51(14), 8897-903. https://doi.org/10.1103/PhysRevB.51.8897

Marinelli, M., et al., 1996, Effect of spin-system fluctuations on heat transport in close to the Néel temperature, Physical Review B-Condensed Matter and Materials Physics, 54(6), 4087-92. https://doi.org/10.1103/PhysRevB.54.4087

Mercuri, F., Buonora, P., et al., 2018a, Metastructure of illuminations by infrared thermography, Journal of Cultural Heritage, 31, 53-62. https://doi.org/10.1016/j.culher.2017.10.008

Mercuri, F., Caruso, G., et al., 2018b, Interface thermal conductance characterization by infrared thermography: A tool for the study of insertions in bronze ancient statuary, Infrared Physics and Technology, 90, https://doi.org/10.1016/j. infrared.2018.02.002

Mercuri, F., Gnoli, R., et al., 2013a, Hidden text detection by infrared thermography, Restaurator, 34(3), 195-211. https:// doi.org/10.1515/res-2013-0011

Mercuri, F., Orazi, N., Paoloni, S., et al., 2017a, Pulsed thermography applied to the study of cultural heritage, Applied Sciences, 7(10), 1010. https://doi.org/10.3390/app7101010

Mercuri, F., Orazi, N., Zammit, U., et al., 2017b, The manufacturing process of the Capitoline she wolf: A thermographic method for the investigation of repairs and casting faults, Journal of Archaeological Science: Reports, 14(September), 199-207. https://doi.org/10.1016/j.jasrep.2017.05.051

Mercuri, F., Paoloni, S., et al., 2013b, Study of the smecticA-hexaticB phase transition in homeotropic single domain samples of 65OBC liquid crystal by photopyroelectric calorimetry, Journal of Chemical Physics, 138(7), https://doi.org/ $10.1063 / 1.4791707$

Mercuri, F., Paoloni, S., et al., 2017c, Pulsed infrared thermography applied to quantitative characterization of the structure and the casting faults of the Capitoline she wolf, Applied Physics A: Materials Science and Processing, 123(5), https://doi.org/10.1007/s00339-017-0958-6

Mercuri, F., Paoloni, S., et al., 2018c, Infrared emission contrast for the visualization of subsurface graphical features in artworks, Infrared Physics and Technology, 89, 223-30. https://doi.org/10.1016/j.infrared.2018.01.012

Mercuri, F., et al., 2003, Critical behavior of thermal parameters at the smectic-a-hexatic-B and smectic-A-smectic-C phase transitions in liquid crystals, Physical Review E-Statistical Physics, Plasmas, Fluids, and Related Interdisciplinary Topics, 68(5), 1-0. https://doi.org/10.1103/PhysRevE.68.051705

Nuzzo, M. (n.d.) La Theotókos di Santa Maria in Cosmedin: Un contributo per la figura del pittore romano Giovanni Piacere, in "Domus sapienter staurata". Scritti di storia dell'arte per Marina Righetti, Silvana Editoriale, Cinisello Balsamo, 398-407.

Orazi, N., et al., 2016, Thermographic analysis of bronze sculptures, Studies in Conservation, 61(4), https://doi.org/ $10.1179 / 2047058415$ Y.0000000025

Orazi, N., et al., 2019, The boxer at rest and the Hellenistic prince: A comparative thermographic study, Journal of Archaeological Science: Reports, 24(January), 115-21. https://doi.org/10.1016/j.jasrep.2018.12.016

Paoloni, S., Mercuri, F., and Zammit, U., 2016, Simultaneous specific heat, thermal conductivity and imaging evaluations in thin samples of $8 \mathrm{CB}$ liquid crystal dispersed with microemulsion of DDAB/water micelles, Journal of Chemical Physics, 145(12), https://doi.org/10.1063/1.4963342

Philippi, I., et al., 1995, Measurement of thermal diffusivities through processing of infrared images, Review of Scientific Instruments, 66(1), 182-92. https://doi.org/10.1063/1.1146432

Pucci, M., et al., 2015, Active infrared thermography applied to the study of a painting on paper representing the Chigi's family tree, Studies in Conservation, 60(2), 88-96. https://doi.org/10.1179/2047058413Y.0000000117

Russo, G., 2013, Antoniazzo Romano, Università degli Studi di Napoli ‘Federico II'. 
Sfarra, S., et al., 2018, A multi-technique nondestructive approach for characterizing the state of conservation of ancient bookbindings, Journal of Thermal Analysis and Calorimetry, 132(2), 1367-87. https://doi.org/10.1007/s10973-0186997-1

Zammit, U., et al., 1988, Photoacoustics as a technique for simultaneous measurement of thermal conductivity and heat capacity, Journal of Physics E: Scientific Instruments, 21(10), 935-7. https://doi.org/10.1088/0022-3735/21/10/004

Zammit, U., et al., 2011, Effect of quenched disorder on the RI-RV, R II-RI, and liquid-RII rotator phase transitions in alkanes, Journal of Physical Chemistry B, 115(10), 2331-7. https://doi.org/10.1021/jp111067z 